\title{
PARÁFRASE E POLISSEMIA: PRODUÇÕES TEXTUAIS ESCRITAS NA ESCOLA
}

\author{
MARINHEIRO, Thaís Silva ${ }^{1}$ \\ BORGES, Fabiana Cláudia Viana ${ }^{2}$
}

\begin{abstract}
RESUMO: Hoje, percebe-se que a correção gramatical e a parte estrutural de uma produção textual escrita são mais valorizadas em relação aos argumentos e à própria autoria. Por conseguinte, deparamo-nos, muitas vezes, com textos escritos na escola sem construções argumentativas que, de fato, extrapolam um lugar comum, de sentidos previsíveis. Muitos alunos até procuram produzir um texto argumentativamente bem escrito, mas a preocupação com a gramática e a parte estrutural prevalece. Assim, observou-se que a leitura parafrástica ainda permanece em sala de aula, com atividades que não permitem a assunção do sujeito-aluno em sujeito-autor em seus textos, e, para que o aluno "se torne" autor, é preciso que ele faça uso da leitura polissêmica e constitua seu próprio arquivo. Partindo desses pressupostos, pretendeu-se, com esta pesquisa, embasada pela teoria da Análise de Discurso francesa, apresentar análises de textos escritos produzidos por alunos em fase de preparação para o vestibular, focando na assunção e/ou interdição da autoria. Para isso, as condições de produção dadas foram relevantes para as análises, isto é, o "Curso Preparatório para o Vestibular", trabalho de caráter voluntário, oferecido aos alunos de $3^{\circ}$ ano do Ensino Médio da Escola Estadual Capitão Antônio Justino Falleiros, na cidade de Ituverava-SP, espaço esse que permitiu observar como o trabalho com textos de diferentes tipologias e como as correções realizadas pelo professor, considerado como o corretor do texto, contribuem, ou não, para a produção de textos polissêmicos.
\end{abstract}

Palavras-chave: Leitura. Escrita. Paráfrase. Polissemia. Vestibular.

\section{PARAPHRASE AND POLISSEMY: TEXTUAL PRODUCTION WRITTEN AT SCHOOL}

\begin{abstract}
SUMMARY: Nowadays one realizes that the grammatical correction and the structural part of a written textual production are more valuable concerning the arguments and the authorship itself. Consequently, we often see texts written at school without argumentative constructions that actually extrapolate a commonplace with predictable meanings. Many students do try to produce an argumentatively well written text but their worrying about grammar and the structural part prevails. Thus, we can observe that the paraphrastical reading still remains in the classroom with activities that don't allow the ascension of the student-subject to student-author in their texts and for the student "to become" the author it's necessary they practice the polissemical reading and build up their own archive. Considering these presuppositions, the very intention of this research, based on the french discourse analysis theory, is to present written text analysis produced by students getting ready for the college admission exam focusing on the ascension and/or interdiction of authorship.To do so, the established production condictions were relevant to the analysis, that is, the "College-prep", a volunteer work offered to students from the 3rd grade of the State High School Capitão Antônio Justino Falleiros in Ituverava-SP, allowed to check how the work with different types of texts as well as the corrections performed by the teachers, considered as the spelling correctors, may contribute or not to the production of polissemical texts.
\end{abstract}

Keywords: Reading. Writing. Paraphrase. Polissemy. College Admission Exam.

\footnotetext{
${ }^{1}$ Graduando no Curso de Letras. E-mail: thaismarinheiro@terra.com.br

${ }^{2}$ Orientadora, Mestre em Linguística. Docente da FE/FFCL.
} 


\section{INTRODUÇÃO}

Esta pesquisa tem como propósito apresentar análises de textos produzidos por alunos de terceiro ano do Ensino Médio em fase de preparação para o vestibular e verificar se esses alunos se colocam como autores ou escritores de seus textos sustentando seus argumentos com o uso da polissemia ou partilhando da ideologia dominante. Dessa forma, espera-se inferir, mesmo sendo um trabalho de curta duração, sobre a necessidade de o aluno constituir seu arquivo para que haja a assunção da autoria, pois não bastam bons argumentos para produzir um texto polissêmico, é necessário que o aluno crie um sentido "novo", assim como afirma Orlandi (2001, p.36), “é a ruptura de processos de significação”, ou seja, poderá fazer novas interpretações do assunto tratado, e, dessa forma, deixa de ficar no eixo do previsível, no campo da paráfrase, é o que acontece com os recortes das análises: os alunos têm bons argumentos, mas não conseguem desenvolvê-los, assim, permanecem no senso comum.

Para a elaboração deste trabalho, optou-se por ministrar aulas voluntárias as quais visam contribuir para a assunção da autoria e a produção de textos polissêmicos. Para isso, as condições de produção são indispensáveis para as análises, isto é, o "Curso Preparatório para o Vestibular", oferecido à comunidade junto ao Programa Escola da Família e aos alunos do terceiro ano do Ensino Médio da Escola Estadual de Ituverava-SP - Capitão Antônio Justino Falleiros sendo aulas aos sábados com duração de duas horas durante dois meses. A escolha da escola se deu por dois motivos: primeiro, por ser onde a pesquisadora concluiu seu Ensino Médio; e, segundo, por ser a única escola pública de Ensino Médio da rede estadual da cidade.

Este trabalho está disposto em duas seções, além das considerações finais. $\mathrm{Na}$ primeira, serão apresentados os pressupostos teóricos, o conceito de autoria, por Orlandi (1996a) e Tfouni (2008); paráfrase e polissemia, por Orlandi (2001, 2003); argumentação, por Orlandi (1996a), Pacífico (2002) e Guimarães (2002); arquivo, por Pêcheux (1997a) e Romão e Pacífico (2006), assim como os conceitos de deriva, discurso e outros propostos pela Análise de Discurso de linha francesa, que embasa esta pesquisa. Na segunda seção, estão os recortes e as análises dos textos escritos pelos alunos. Pode-se adiantar que a necessidade que o aluno encontra de escrever conforme o professor pede, e quando lhe é dada "liberdade" para escrever, faz com que o discente continue formatado aos padrões tecnicistas das instituições de ensino e não se permite o uso da polissemia.

Por último, apresentar-se-ão as considerações finais, as quais pretendem, assim como todo o trabalho, provocar reflexões sobre o ensino da leitura na sala de aula. Principalmente por se tratar de alunos do último ano do Ensino Médio, pois se cria o estereótipo que esse 
aluno saberá escrever e irá produzir um texto que o aprovará no vestibular, mas, infelizmente, não é o que mostram as análises.

\section{PRESSUPOSTOS TEÓRICOS}

\section{A CONSTRUÇÃO DO ARQUIVO}

Ao se falar em leitura em sala de aula, percebe-se que, na fala do professor, há o predomínio de um discurso que Orlandi (2003, p. 15) denomina de discurso autoritário. Essa autora apresenta a tipologia discursiva e classifica-a como: lúdico, polêmico e autoritário e inclui, neste último, o discurso pedagógico ${ }^{3}$. Para a 'escolha' do tipo discursivo que se faz presente na sala de aula, há dois processos que são usados: o parafrástico e o polissêmico. $\mathrm{O}$ polissêmico é, segundo a autora, "a tensão constante estabelecida pela relação homem/mundo, pela intromissão da prática e do referente, enquanto tal, na linguagem", ou seja, é a constituição de um novo sentido, é a relação que o autor faz entre o que já se conhece com sua formação ideológica a partir do seu interdiscurso. Já a paráfrase é o sentido já existente é a retomada daquilo que já fora dito. Não se pode simplesmente desconsiderá-la, pois é do sentido existente que se forma o novo, o polissêmico.

$\mathrm{Na}$ maioria das vezes, nas práticas discursivas pedagógicas, o predomínio é do discurso autoritário o qual não abre espaço para o discurso lúdico e nem tampouco para o polêmico. Orlandi (2001, p.87) explicita:

\footnotetext{
Não se deve assim tomar, por exemplo, o lúdico no sentido do brinquedo mas do jogo de linguagem (polissemia) e não se deve tampouco tomar pejorativamente o autoritário como um traço de caráter do locutor, uma questão moralista, mas uma questão do fato simbólico (a injunção à paráfrase).
}

Por isso, nas produções escritas em salas de aula, os alunos são formatados a escreverem segundo os estereótipos, como propõe o docente.

Dessa forma, o discente acredita posicionar-se como autor, mas, na verdade, ele não passa de escritor, para ser autor é preciso levar em consideração suas condições de produção, e principalmente, dar sentido ao que escreve, é claro que este não está pronto, pois deve ser levada em consideração sua relação com a historicidade, exterioridade e interdiscurso. Como

\footnotetext{
${ }^{3}$ Orlandi (2003, p. 15) define o lúdico como sendo o discurso "em que o objeto está presente e os interlocutores se expõem a essa presença, a polissemia é aberta e o exagero é o non-sense. $\mathrm{O}$ discurso polêmico, no qual o objeto também é presente, os interlocutores procuram dominar o referente, dando-lhe uma direção, indicando perspectivas particularizantes, a polissemia, nesse tipo de discurso, é controlada e o exagero considerado uma injúria. Por fim, o discurso autoritário é aquele em que o referente é "ausente", oculto pelo dizer, os interlocutores não existem, mas sim um agente exclusivo, nesse a polissemia é contida." E por último, o discurso pedagógico o qual Orlandi (op. cit.) classifica como autoritário, pois o que se vê na sala de aula é a imposição da voz do professor que não abre espaço para a voz do aluno.
} 
afirma Guimarães (1995, p. 37), “o sentido de um acontecimento são efeitos da presença do interdiscurso, do cruzamento de discursos diferentes no acontecimento", Costa (2006, p.266) ainda complementa "o interdiscurso constitui o sujeito e o sentido, no momento em que põe a língua em funcionamento".

Entende-se o interdiscurso aqui como sendo a memória discursiva, Orlandi (2001, p.54) afirma: "o interdiscurso - a memória discursiva - sustenta o dizer em uma estratificação de formulações já feitas, mas esquecidas e que vão construindo uma história de sentidos". Ou seja, é o que torna possível o dizer e retoma sobre a forma de pré-construído, o já-lá (já-dito), o sentido pode ser novo (polissêmico), mas não inédito, pois ele não nasce do "nada", é retomado sob forma de algo que já fora dito

Alguns alunos julgam-se autores de seus textos, mas para ser autor, segundo a Análise do Discurso de linha francesa que embasa esta pesquisa, não basta apenas escrever, é preciso que ele faça uma relação entre a sua posição social e a formação ideológica da qual compartilha.

No que diz respeito à autoria, Orlandi (1996a, p.61) afirma que:

Função sujeito-autor é a função em que o sujeito falante está mais afetado pelo contato social (submetido às regras das instituições); é a função que o eu assume enquanto produtor de linguagem. Para que o sujeito se coloque como autor, precisa estabelecer uma relação com a exterioridade, ao mesmo tempo em que ele se remete à sua própria interioridade (ele aprende a assumir o papel de autor e aquilo que ele implica). Para ser autor, o sujeito precisa estar inserido em uma cultura, uma posição no contexto histórico-social.

Nas aulas de redação das escolas, principalmente nas terceiras séries do Ensino Médio, pede-se ao aluno que construa textos argumentativos, mas o que ocorre é apenas uma tentativa para cumprir a tarefa, de tal forma que, muitas vezes, o aluno, por não conseguir posicionar-se como autor, não consegue sustentar seu argumento. A autoria está relacionada ao arquivo, às condições de produção, ao contexto histórico-social ${ }^{4}$, Tfouni (2008, p. 141-142) complementa “o sujeito ocupa a posição de autor quando retroage sobre o processo de produção de sentidos, procurando 'amarrar' a dispersão que está sempre virtualmente se instalando devido à equivocidade da língua". Argumentar exige responsabilidade pelo seu dizer, como afirma Orlandi (1996a, p. 79). Se todos esses fatores, os quais foram mencionados, não estiverem

\footnotetext{
${ }^{4}$ Orlandi (1996b, p. 67-68) explica que “o social se apresenta não como traços sociológicos empíricos (classe social, idade, sexo, profissão) mas como formações imaginárias que se constituem a partir de relações tal como elas funcionam no discurso, havendo em toda língua mecanismos de projeção para que se constitua essa relação entre a situação e a posição dos sujeitos, discursivamente significativa. O histórico é definido não como fatos e datas, como evolução e cronologia, mas como significância, ou seja, como trama de sentidos, pelos modos como eles são produzidos".
} 
entrelaçados o texto perde o sentido, e quando isso acontece o aluno é levado para o senso comum, permanece na paráfrase.

Para Pacífico (2002, p. 120-121):

[...] argumentar é uma "arte" difícil e, ao perceber esta dificuldade, na falta de uma argumentação eficiente, o sujeito migra para outra região do sentido e usa do genérico, do senso comum, dos ditos populares, enfim, do já-lá para instaurar a argumentação nos textos.

Com esta citação, pode-se compreender uma das formas de esquecimento no discurso trazido por Pêcheux (1997b, p. 173), neste caso, o esquecimento número dois: "que é da ordem da enunciação" o qual faz parte do discurso parafrástico em que se pensa que o discurso deve ser dito de uma única forma, com aquelas palavras, daquela maneira e não de outra. Há ainda o outro esquecimento, o de número um, também chamado esquecimento ideológico: ele é da instância do inconsciente e resulta do modo pelo qual somos afetados pela ideologia. Por esse esquecimento, tem-se a ilusão de que somos a origem do que dizemos quando, na realidade, retomamos sentidos pre-existentes.

Retoma-se, aqui, o sentido de argumentação, citado anteriormente, sob a perspectiva de Guimarães (2002), a argumentação não é derivada de condições de verdade ou de seu caráter lógico. Argumentar com um determinado enunciado é apresentar seu conteúdo como devendo conduzir o interlocutor a uma determinada conclusão e também um conteúdo.

Tfouni (2008, p. 153) explicita que "a deriva refere-se ao fato de que o sentido sempre pode vir a ser outro, e, quando ocorre sem ser controlada, instala uma ausência de coerência no texto. Refere-se ao interdiscurso, e se substancia em um relançar ínfimo de significações"

Escrever um texto com argumentação só é possível quando o sujeito tem arquivo (PÊCHEUX, 1997a, p. 57), ou seja,

\footnotetext{
é o campo de documentos pertinentes e disponíveis sobre uma questão. Há gestos de leitura que constroem o arquivo, que dão acesso aos documentos e que dão ao modo de apreendê-los nas práticas silenciosas de leitura "espontânea". Essas leituras são organizadas e elas dispõem sobre a relação do literal e do interpretativo.
}

Posteriormente, nas análises, perceber-se-á a necessidade de a escola contribuir para que o aluno compreenda a importância de enriquecer seu arquivo, pois "só o acesso ao arquivo discursivo possibilita a leitura como um processo de construção que vai além dos sentidos literais" (ROMÃO; PACÍFICO, 2006, p. 19), ou seja, a partir das leituras feitas, o aluno constrói seu dispositivo teórico que dá acesso à sua memória discursiva, permitindo, assim, produzir gestos de interpretação. Do contrário, quando não se tem um dispositivo teórico bem trabalhado, com leituras suficientes para se tratar determinado assunto, o texto 
permanece na mesmice, no eixo da previsibilidade. Esta pode ser entendida como algo que é esperado, que não passa do sentido literal, do mesmo, o estereótipo, o consenso.

$\mathrm{O}$ aluno quando não possui seu interdiscurso bem formado para escrever sobre determinado assunto ele parte para a repetição, Orlandi (1996b, p. 70) distingue três tipos de repetição, podendo ser: empírica, essa não historiciza, o aluno fala / escreve 'sem pensar', fica no nível da paráfrase; formal, nessa o aluno reproduz frases, também não historiciza, tem rigor gramatical, mas continua na paráfrase; e histórica em que o aluno "inscreve o dizer no repetível enquanto memória constitutiva”. É na repetição histórica que o aluno constitui-se como autor de seu texto, ele faz a língua significar, quando remete ao seu interdiscurso, é nessa noção que "sentido, memória e história se intrincam".

\section{A PARÁfrase E A POLISSEMia NA FORMAÇÃo do ALUNO E DO PROFESSOR}

Na sala de aula, o papel do professor não é apenas passar atividades e dar nota avaliativa para que os alunos sejam promovidos para a próxima série. É necessário dar informações de como desenvolver tais atividades, principalmente quando se tratam de atividades de leitura, o docente deve-se mostrar um leitor atuante, e assim ter seu arquivo bem constituído.

Pensar na constituição do arquivo do aluno é pensar, também, tal como apresenta Costa (2008), na formação e atualização do arquivo do professor, pois se este não estiver com seu arquivo bem formulado não há como alimentar o arquivo do aluno, por conseguinte, não há a possibilidade de contribuir para a assunção do sujeito-aluno para a função-autor.

Quando o aluno escreve um texto não partilhando de suas histórias de leitura, esse texto permanece no eixo do previsível, alguns motivos para isso acontecer é por o sujeito partilhar de uma ideologia dominante que escreve conforme o senso comum. Assim, Orlandi (1996a, p.87) traz a noção de dois fatores determinantes para a previsibilidade em relação aos processos de significação: "1- os sentidos se sedimentam de acordo com as condições em que são produzidos; e 2- dada a relação entre os textos, o conjunto dessas relações indica como o texto deve ser lido".

Conforme será mostrado nas análises, o aluno que permanece no eixo do senso comum, ao escrever um texto previsível, possui um discurso parafrástico. Por outro lado, quando o aluno se posiciona como autor em seus textos, ele dá indícios de suas leituras, e faz com que o leitor siga o mesmo caminho bibliográfico por ele percorrido. Dessa forma, o leitor utilizará a mesma linha de leitura que foi usada pelo autor, mas poderá chegar a conclusões distintas por se tratar de texto, por haver a polissemia que, segundo Orlandi (2001, p. 36) "é a 
ruptura de processos de significação, ou seja, poderá fazer novas interpretações do assunto tratado".

Para que o aluno possa posicionar-se como autor, as condições de produção são imprescindíveis. O que se espera não é um aluno formatado, moldado nos padrões escolares, como já fora dito, e como se vê nas instituições de ensino. Espera-se do professor que seja apresentado o tema proposto a fim de discuti-lo, e, dessa forma, o aluno consiga posicionar-se como autor com responsabilidade pelo seu dizer, argumentos convincentes e controle do equívoco, e da deriva os quais fazem parte dos aspectos da incompletude, conforme apresentado por Orlandi (1996b, p. 76-77):

[...] se o fecho tem sua eficácia na produção do efeito de unidade, de coerência e de não-contradição, porém pela incompletude da linguagem - todo texto tem a ver com outros textos, existentes, possíveis ou imaginários, pois eles têm sobretudo uma relação necessária com a exterioridade, estabelecendo assim suas relações de sentido - e pela dispersão do sujeito - que aparece em sua descontinuidade no texto - o autor não realiza jamais o fechamento completo do texto, aparecendo, como diz Pêcheux, ao longo do texto pontos de deriva possíveis, oferecendo lugar à interpretação, ao equívoco, ao trabalho da história na língua.

Guimarães (2002, p.15) ainda completa em relação à incompletude: “ou seja, o que digo não é completo, parte do seu sentido está no que os outros dizem e vice-versa".

O sujeito, ao escrever, possui uma formação discursiva - em que Orlandi (1996a, p. 58) define ser "aquilo que numa formação ideológica dada (a partir de uma posição sóciohistórica dada) determina o que pode e deve ser dito" e quer posicionar-se ante a ideologia da qual compartilha. Dessa forma, Foucault (1969) apud Orlandi (1996a, p. 53) define o sujeito como uma descontinuidade e o texto como espaço de divergências múltiplas. Tudo porque, o sujeito não compartilha de apenas uma formação discursiva, e isso é encontrado nos textos contraditórios, quando, muitas vezes, o aluno não sabe posicionar-se de maneira que não ocorra a falha (equívoco).

Pacífico (2002, p. 38) traz a seguinte afirmação: "para Pêcheux (1995), existe uma articulação entre ideologia e inconsciente na constituição do sujeito", e explica:

Pêcheux traz este conceito para o discurso e mostra que, no discurso, isto se dá pela interpelação do indivíduo em sujeito de seu discurso, o que acontece devido a sua identificação com a formação discursiva que o domina, de tal forma que o sujeito reinscreve o interdiscurso (o já-lá) no "seu próprio" discurso, assumindo a formasujeito. Desta forma, é no interior de uma formação discursiva que se realiza o assujeitamento do sujeito discurso.

Orlandi (1996, p. 53) explica, a partir de Pêcheux, que essa expressão forma-sujeito é usada para se referir ao sujeito que é afetado pela ideologia. 
Hoje, o mínimo esperado pelas escolas, em séries inicias, é que o aluno saiba ler e escrever, mas será que esse ato de ler é ainda praticado quando esse mesmo aluno cursa o Ensino Médio? Ou seja, será que o aluno é instigado a escrever polissemicamente? Essa é uma das questões deste trabalho de conclusão de curso. Sabe-se que a leitura é implantada na sala de aula, por outro lado não é trabalhada como deveria ser - em algumas escolas, não se está generalizando - assim não é permitida ao discente a sua interpretação, que, muitas vezes, é dada como correta a do livro didático ou a do professor, e acaba por permanecer na paráfrase, no campo do inteligível ${ }^{5}$, da decodificação, com isso Pacífico (2002, p. 31) traz a noção de fôrma-leitor:

[...] existem lugares de sujeito-leitor que assumem o que chamamos de fôrma-leitor (no sentido de fôrma, molde), fôrma esta determinada pela ideologia dominante em cada formação social, que tem como objetivo limitar o processo de significação do sujeito, sua possibilidade de interpretação; por isso, o sujeito-leitor que assume a fôrma-leitor realiza uma leitura inteligível (parafrástica), em que o controle do sentido está sempre presente.

Costa (2008) ainda apresenta a noção de fôrma-professor que é caracterizada por "aquele que, assim como acontece na fôrma-leitor, em se tratando de alunos, parafraseia tudo o que é considerado bom para determinadas finalidades e repassa isso (ainda sob a forma de paráfrase) para o aluno".

Retomando a concepção de Costa (2006) em relação ao sentido, sabe-se que, quando o sujeito posiciona-se como autor, este, sustentado pelo seu interdiscurso, produz um sentido, não unívoco, pois é sempre passível de falha. Canguilhem (1990), apud Pêcheux (1997a, p. 62): "o sentido é relação à, o homem pode jogar com o sentido, desviá-lo, simulá-lo, mentir, armar uma cilada". Homem aqui pode ser interpretado como sujeito, autor.

Pêcheux (op. cit.) esclarece, ainda, que esse sentido só é permitido porque a língua "encobre" - termo usado pelo autor - esse jogo, como se vê a seguir:

É esta relação entre língua como sistema sintático intrinsecamente passível de jogo, e a discursividade como inscrição de efeitos lingüísticos materiais na história, que constitui o nó central de um trabalho de leitura do arquivo (PÊCHEUX, 1997, p. 63)

Em relação à autoria, pode-se afirmar que a noção que sustenta este trabalho diferencia-se da noção de autor trabalhado por Foucault (1969), pois, para ele, deve-se compreender o autor como uma função e definir as condições, os domínios em que essa função exerce. Completa ainda que "a função autor é, assim, característica do modo de

\footnotetext{
${ }^{5}$ Orlandi (1996a) traz as seguintes considerações: Inteligível: a que se atribui sentido - codificação; interpretável: a que se atribui sentido, leva em conta o contexto, entende-se o enunciado; compreensível: é a atribuição de sentidos considerando o processo de significação, busca compreender os possíveis sentidos do texto.
} 
existência, de circulação e de funcionamento de alguns discursos no interior de uma sociedade”. Já para Orlandi (1987) "a função discursiva autor é aquela que o eu assume enquanto produtor da linguagem" como nos mostra Rodrigues (2006). Fernandes (2009, p.408) entende "a autoria como uma função que leva a relacionar as escolhas promovidas pelo aluno-autor a uma apropriação de textos do interdiscurso em gestos de seleção ou no estabelecimento de oposições".

O aluno ao escrever seu texto parte de sua formação imaginária, que pode ser entendida como traz Orlandi (2001, p. 40) "não são os sujeitos físicos nem os seus lugares empíricos como tal, isto é, como estão inscritos na sociedade, e que poderiam ser sociologicamente descritos, que funcionam no discurso, mas suas imagens que resultam de projeções", assim, ele (aluno) posiciona-se positiva ou negativamente, mas não consegue atingir o leitor, não consegue convencê-lo, persuadi-lo argumentativamente. Uma das causas disso pode ser o fato de não possuir leitura suficiente para tal (arquivo), pois como foi dito anteriormente, é nos seus textos que os alunos mostram as leituras que fazem / fizeram. E essa teoria é também defendida por Orlandi (1996a, p. 91): “a escrita, ou seja, a redação é o meio de se ter acesso à leitura do aluno".

Mas ter seu arquivo bem constituído não é fator único para tornar-se autor e produzir um texto parafrástico ou polissêmico, conforme Gregolin (2001), como mostra em Fernandes (2009, p. 409): "todo autor é sempre um leitor que se apropria de textos para compor um novo texto formado por descontinuidades e por dispersões". Em suma, o contraste feito entre Orlandi (1996a) e Gregolin (2001) refere-se ao fato de que ter o arquivo bem constituído é necessário para se fazer autor, mas apenas o arquivo não é suficiente, pois em muitas situações o escritor entende do assunto abordado como tema para a escrita, porém não consegue desenvolvê-lo, e, para isso, mantém-se no senso comum, usa do estereótipo na certeza de um argumento convincente.

Como serão apresentados nas análises, os alunos escrevem um texto sobre o tema “Televisão" com apenas as informações que possuem em seu arquivo; em um outro momento, são convidados a escrever novamente sobre o mesmo tema - lembrando que são aulas voluntárias -, mas antes o professor lhes dá textos informativos, de opinião, charges como uma coletânea de dados (propostas anexas) para enriquecer a memória discursiva desses alunos. Quando eles releem seus textos, não a maioria, alguns ainda permanecem no discurso dominante, percebem que há alterações a se fazer, pois se colocam no lugar de leitores e não de autores.

Isso é entendido por Fernandes (2009, p. 411-412) como função-autor-leitor: 
O autor-leitor de outros textos, agora, assume um novo papel: a de leitor-avaliador de seu próprio produto. Nessa atitude, depara-se com a formação imaginária que faz de si mesmo, percebe a artificialidade da posição tomada, dialoga com seus enunciados e com sua memória discursiva.

Pacífico (2002, p. 53) ainda acrescenta:

\begin{abstract}
"Isso significa que o sujeito que produz um discurso, principalmente um discurso argumentativo, deve ocupar as posições de autor e de leitor, criando assim, estratégias discursivas que antecipem as possibilidades de respostas do outro e, a partir destas, possa construir sua argumentação."
\end{abstract}

Para as leituras que os alunos fazem, as quais são observadas em seus textos, Orlandi (1996a, p. 87) traz a noção de história das leituras: "todo leitor tem sua história de leituras. As leituras já feitas configuram - dirigem, isto é, podem alargar ou restringir - a compreensão do texto de cada leitor específico", é a confirmação de que o exterior à linguagem afeta os sentidos produzidos em uma leitura.

Orlandi (1996b, p. 63) vê “a questão ideológica inscrita na interpretação”, em que Pacífico (2002, p. 70) explica "os sujeitos constroem pontos de deriva em relação ao tema proposto para a dissertação porque estão inseridos em outra formação discursiva". Para o aluno é mais fácil expor sua opinião, falar a partir de determinada formação ideológica da qual compartilha do que criar um sentido novo para o seu texto, do que pensar em outra posição para sua formação discursiva, mesmo porque, não se pode exigir isso do aluno, pois os professores, também formatados ao livro didático, como afirma Costa (2008) fôrmaprofessor, não mostram essa possibilidade de interpretação aos alunos.

\title{
ANÁLISE EM SALA DE AULA
}

Pretende-se apresentar análises de textos escritos produzidos por alunos em fase de preparação para o vestibular e concurso, focando nas assunção e/ou interdição da paráfrase, da polissemia e da autoria. Para isso, as condições de produção dadas serão relevantes para as análises, isto é, o "Curso Preparatório de Redação", trabalho de caráter voluntário, oferecido à comunidade e aos alunos de $3^{\circ}$ ano do Ensino Médio da Escola Estadual Capitão Antônio Justino Falleiros, na cidade de Ituverava-SP, com aulas ministradas aos sábados e com duração aproximada de duas horas, observando, dessa maneira, como o trabalho com textos de diferentes tipologias e as correções realizadas pelo professor, considerado como o corretor do texto, contribuem, ou não, para a produção de textos polissêmicos.

\section{AS CONDIÇÕES DE PRODUÇÃO}

Sabe-se que, nas instituições de ensino, o aluno escreve conforme o discurso do 
professor, podendo ser, assim como interpreta Orlandi (2003, p. 15), lúdico, polêmico e/ou autoritário, neste último também se encontra o pedagógico, o qual "vê na sala de aula a imposição da voz do professor que não abre espaço para a voz do aluno”. Por este motivo, tem-se, como intuito deste trabalho, o foco nos processos polissêmicos e parafrásticos relacionados à autoria e à argumentação do aluno em sala de aula e, desta forma, analisar se há nos textos preparo para a escrita de acordo com sua memória discursiva. Para isso, houve duas condições de produção.

Em primeiro momento, foi pedido aos alunos que escrevessem, em sala de aula, sobre o tema Televisão, e se posicionassem argumentativamente, tendo como coletânea um texto retirado do livro didático, o qual é usado por eles em sala de aula. Além disso, nada a respeito do assunto fora trabalhado e comentado pela professora, a única instrução foi o número dez como mínimo de linhas escritas. A intenção desta atividade é mostrar como o trabalho, sem preparação do arquivo, não contribui para a assunção da autoria. "A escrita, ou seja, a redação é o meio de se ter acesso à leitura do aluno" (ORLANDI, 1996a), é a partir desta afirmação que a professora pretende conhecer a escrita dos alunos, reconhecer a ideologia da qual compartilham e verificar se, nos textos, haverá polissemia e argumentação, e se o aluno sabe posicionar-se como autor de seu texto. Nas instituições de ensino, nas aulas e/ou laboratórios de redação, é comum o professor pedir esse tipo de atividade, mas se o professor não tiver um objetivo específico para pedir tal atividade e observar apenas se o aluno tem construção gramatical, nada irá contribuir para a formação desse aluno como autor de seu texto. Mesmo porque Orlandi (1996a, p. 61) afirma que a autoria "é a função que o eu assume enquanto produtor da linguagem", função essa que não é permitida em sala de aula por conta da ideologia dominante.

$\mathrm{Na}$ segunda condição de produção, foi pedido aos alunos que escrevessem sobre o mesmo tema (televisão), mas, desta vez, com um diferencial, a professora lhes levou uma coletânea com diferentes tipologias textuais, como charges, informativos e textos de opinião, todos retirados da internet, para mostrar aos alunos que este veículo também traz informações fidedignas as quais podem ajudar no momento de escrever um texto. Estas informações enriquecem a memória institucionalizada, o arquivo (PÊCHEUX, 1997a) o que possibilita a criação de bons argumentos que, posteriormente, poderão ser retomados pelo interdiscurso, a memória discursiva (PÊCHEUX, 1997b).

Após a explicação, comentários e debates em sala, a professora pediu aos alunos que escrevessem um texto, ainda sobre televisão, mas que isso fosse feito em casa, sem número mínino ou máximo de linhas. A única exigência foi a de pesquisar em revistas, jornais ou nos 
próprios textos usados em sala algo relacionado à televisão para que eles mesmos constituíssem seu arquivo.

Em suma, pode-se observar que o aluno parafrástico se manteve no óbvio, reproduzindo os dizeres autorizados pela escola, sendo o discurso do professor e as coletâneas também retomadas por ele. Percebe-se assim, que durante a prática escolar, provavelmente, não fora estimulada a leitura para alguns alunos, os quais não buscaram alimentar o arquivo com argumentos construídos pelas leituras de textos extras, de forma que seus argumentos no segundo texto não foram diferentes do primeiro, o texto foi reescrito, mas continuou na paráfrase. Enquanto que em outro texto percebe-se a polissemia, pois houve a busca de diferentes informações para compor o argumento do aluno, ou seja, compor o arquivo, assim, percebe-se suas histórias de leitura enriquecidas no seu interdiscurso.

As análises aqui apresentadas têm como suporte teórico, além das noções já apresentadas, a noção de interpretação tal como Orlandi (1996b) define, ou seja:

O espaço de interpretação no qual o autor se insere com seu gesto - e que o constitui enquanto autor - deriva da sua relação com a memória (saber discursivo), interdiscurso. O texto é a peça significativa que, por um gesto de autoria, resulta da relação do "sítio significante" com a exterioridade (ORLANDI, 1996b, p. 15).

O aluno vai interpretar, mesmo que de forma inconsciente, de acordo com o interdiscurso e o saber discursivo (arquivo). O texto é apenas um dos objetos simbólicos usados pelo aluno para produzir sentido, e nele será possível criar os gestos de interpretação (sítio significante), pois a todo momento está se interpretando, o que pouco se faz é o controle dos pontos de deriva, dessa forma os sentidos escapam, assim, formam-se os equívocos, as falhas da linguagem, as quais apresentaremos nas análises adiante.

\section{CORPUS}

\section{A ARGUMENTAÇÃO E A ASSUNÇÃO DA AUTORIA}

Observe o primeiro recorte, escrito pelo aluno-A.

[1] Pode-se dizer que pelo fato da televisão não trazer somente conteúdos educativos e cultural, é melhor se informar através de jornais e revistas, porém, hoje tem um custo caro e pode não ser acessível a todos. A televisão traz com rapidez tudo que acontece ao redor do mundo, como por exemplo pode-se citar o Jornal Nacional que divulgou informações completas do terremoto no Haiti instantes depois da tragédia. ${ }^{6}$

Percebe-se que este aluno parte do pressuposto de que não é bom assistir aos canais de televisão por haver programas "indesejados", ainda dá ao leitor uma opção para se informar, de forma que ainda salienta ser um meio pouco acessível. Este aluno dá indício de que irá

\footnotetext{
${ }^{6}$ Todos os recortes extraídos dos textos dos alunos são apresentados conforme escrito por eles.
} 
sustentar seu argumento, mas deixa a ideia e parte para outro argumento, sem desenvolver ou retomar o primeiro. Assim, os sentidos escapam, o que é entendido por Tfouni (2008, p. 153) como deriva: "uma ausência de coerência". Ainda assim, seus argumentos produzidos na condição [A1] não diferem do texto produzido na condição [A2]. Mesmo este texto apresentando poucos problemas gramaticais e até arriscar um argumento "improvável”, o terremoto no Haiti, continua no eixo da previsibilidade.

Ainda fazendo referência sobre o aluno-A, o prevalecimento do sentido dominante, sobretudo no que diz respeito à responsabilidade dos pais ou dos responsáveis pelo que as crianças assistem na televisão, é bastante comum nos textos analisados, como podemos observar no recorte abaixo:

[2] Quando devidamente orientada, a criança não utiliza os canais de forma incorreta; a televisão traz liberdade de uso, fazendo com que só se obtenha canais com cenas e informações impróprias, quem queira.

Nesse texto, percebe-se a presença do sentido dominante pela expressão "assiste quem quer", ou seja, transfere-se a responsabilidade por receber informações impróprias, a partir de programas inadequados, ao espectador, ou mesmo aos pais. Em nenhum dos textos analisados que citam a criança e a televisão há menção à responsabilidade das emissoras pela veiculação dos conteúdos inadequados ao público infantil, mas sim, a atribuição da responsabilidade aos adultos que acompanham essas crianças.

No texto do Aluno-B, na segunda condição de produção, [2], em que se esperava o interdiscurso mais elaborado em relação à primeira condição de produção, não foi o que aconteceu. Conforme já se afirmou, os alunos não estão acostumados a ter "liberdade" para a escrita, tanto que não pensam no seu possível leitor; dessa forma, deixam abertos pontos de "fuga" do sentido desejado, à deriva, não há o controle da dispersão dos sentidos, conforme se pode verificar no recorte abaixo:

[4] De acordo com alguns críticos, passamos grande parte do nosso tempo na frente da TV, mas, se gastamos tanto tempo assim é porque optamos por dedicar tempo a ela, ou seja, a escolha foi nossa, o tempo é nosso e fazemos com ele aquilo que bem entendermos.

Há, nesse recorte, um argumento muito fraco em relação ao tema proposto, pois o aluno tenta fazer referência à coletânea da condição [1] - proposta em anexo - trabalhada em sala de aula quando cita "de acordo com alguns críticos", mas para o leitor que não conhece esse texto usado como suporte não vai saber de qual crítico se refere.

O recorte a seguir, [5], é do Aluno-C, observe: 
[5] Fora é claro as notícias que chegam em tempo real e a distração, que de uma certa forma é como é escapi da rotina estresante do dia-a-dia. Por tanto a televisão é um bom veículo de comunicação e distração que de uma certa forma se tornou fundamental para o mundo moderno.

O escritor deste texto não consegue esclarecer o que diz, faz uso da repetição quando se utiliza da expressão "de certa forma" mais de uma vez, o que não dá convicção à sua escrita. Ainda, esse aluno não se posiciona como autor, primeiro por não se atentar à pontuação necessária que é um fator de autoria; e segundo por deixar os sentidos soltos abertos à deriva quando afirma que a televisão "se tornou fundamental para o mundo moderno", pois não explicita o motivo de a televisão ser tão importante para o mundo moderno.

Observe os textos do Aluno-D:

[10] Os desenho só tem lutas guerras, morte, rolos, armações e, etc por ex: O PicaPau ele so trapassa só quer levar vantagem entudo. Novelas então só nudez ou perido, traição, prostituição, falsidade, perversidade e, outras mais que nem é bom dizer.

Esse recorte evidencia sentidos moldados pelo discurso pedagógico, ou seja, o aluno parafraseia o discurso do professor, na certeza de que será uma produção garantida; é o caso do exemplo do Pica-Pau, que fora mencionado pelo professor, em sala, numa discussão oral sobre televisão, o aluno reproduziu exatamente como foi dito. Isso exemplifica como o sujeito se identifica com o sentido cristalizado de que se escreve a partir do que disse o professor em sala de aula, estará correto seu texto, esse campo do senso comum não abre espaço para a polissemia. Ainda sobre o recorte [10], veja no recorte [11] o excerto do texto III da coletânea que é parafraseado pelo aluno em [2]:

[11] Os casais não conseguem entender que não é a nudez sem limite o perigo e sim a dose homeopática de ensinamento todos os dias mostrando a eles próprios e aos filhos como se transformarem em perversos, amantes, traidores, infiéis ou até mesmo como se prostituírem sem sair de casa.

A seguir, analisar-se-á o texto do Aluno-E, a partir do recorte abaixo:

[13] Necessita-se de um trabalho vigilante e claro para banir a veiculação dessas propostas de programas que visam uma alta rentabilidade, a difamação, o jogo psicológico. Pois atualmente a acessibilidade está grande e a posição ética em relação a uma certa classificação é precária ou nula.

Esse texto produzido na primeira condição de produção [1] mostra evidentes pontos de autoria, pois estabelece uma relação entre a sua própria interioridade e a exterioridade (ORLANDI, 1996b). O sujeito procura amarrar os sentidos e não dá abertura para a deriva. 
Nota-se a sustentação do argumento, pois o aluno possui arquivo para tal devido às suas histórias de leituras que alimentam seu interdiscurso.

Adiante, no recorte [13], as análises evidenciam assunção de autoria, a presença da polissemia, marcando o lugar da repetição histórica, em que o sujeito instaura discursividade em seu dizer, irrompendo com os processos de significação, possibilitando uma nova interpretação para o assunto tratado:

[13] A televisão tem como função trabalhar os parâmetros informacionais e divertir de uma forma lúdica. Contudo, a atual realidade que se encontra, é uma programação irônica, promíscua, tentadora e, principalmente, que anula a opção do livre arbítrio do indivíduo.

O sujeito desse dizer não cessa suas reflexões com argumentos como "a função da TV é informar e divertir", mas vai além, questiona se a televisão está mesmo cumprindo o seu papel, além de questionar sobre o caráter da programação. Outro fator importante aqui presente é que esse sujeito desliza o sentido sedimentado de que é o expectador quem escolhe o que é bom ou ruim. Para ele, o espectador não pode escolher, pois está submetido às imposições da TV. Enquanto os outros alunos atribuem a responsabilidade da programação a quem a assiste, o Aluno-E sustenta seu argumento afirmando que os responsáveis pela programação são as próprias emissoras, são elas que impõem o horário e o que vai ser assistido, o espectador apenas se resigna com a situação.

\section{CONSIDERAÇÕES FINAIS: A AUTORIA NA SALA DE AULA}

Vale ressaltar que os alunos, escritores dos textos aqui analisados, estão em fase de preparação para o vestibular e/ou concurso, ambas as provas priorizam a parte escrita, de forma que essa modalidade apresenta um peso maior que as questões de múltipla escolha. $\mathrm{Na}$ primeira condição de produção [1], os textos foram escritos em sala, e na segunda condição [2], em casa. Em [2], os alunos tiveram oportunidade para enriquecer seu arquivo e colocar em prática o interdiscurso, apesar do pouco tempo. O que se pôde perceber, pelas análises, foi uma repetição no conteúdo da escrita, os alunos A, B, C e D permaneceram na paráfrase, e o Aluno-E, na polissemia.

A partir dessas análises e a percepção do professor em sala de aula, constata-se que os alunos deixam em evidência a angústia frente à folha em branco, pelo fato de não saberem posicionar-se como autor de seus textos, pois não basta saber escrever corretamente conforme as regras, por muitos decoradas, da construção gramatical, o aluno necessita ter seu arquivo, sua memória institucionalizada, para que não chegue no dia da prova e se deparar com o 
questionamento: o que escrever? Muitos têm a ilusão da linguagem como representação do pensamento, pensam que sabem sobre o que vão falar, os argumentos que serão utilizados, mas quando chega o momento de escrever, falta-lhes "inspiração", termo comum entre os adolescentes nas aulas de redação. O que realmente falta é uma construção de sentidos, é a historização dos sentidos, e o aluno só entenderá quando tiver um arquivo bem constituído, e isso só é possível pelas leituras, só é possível quando o próprio aluno criar sua história de leituras.

Dessa forma, os Alunos A, B, C e D os quais fazem uma leitura inteligível, parafrástica, assumem a fôrma-leitor, noção esta que é trazida por Pacífico (2002) "fôrma esta determinada pela ideologia dominante em cada formação social, que tem como objetivo limitar o processo de significação do sujeito". Enquanto que o Aluno-E faz parte da funçãoautor-leitor (FERNANDES, 2009) que não apenas escreve o texto, mas o lê de forma avaliadora, assim percebe se há pontos de deriva e, quando há, corrige-os.

Pode-se concluir, com as análises, que, para um professor conseguir que seus alunos se tornem autores de seus próprios textos e deixem de ser apenas escritores, é um trabalho árduo. E é preciso tempo para ser desenvolvido de forma que o aluno entenda o que é ser autor, caso contrário ele vai continuar no repetível e, por conseguinte, continuar na paráfrase.

Com este trabalho, foi possibilitada a percepção da sala de aula de uma escola pública em relação ao trabalho que é desenvolvido com a redação dos alunos. Esses são instigados a focar na aprendizagem das construções gramaticais e nos esquemas de redação, que implicam número aproximado de linhas com introdução, desenvolvimento e conclusão. Mesmo que o aluno saiba construir seu texto conforme "mandam" os esquemas mencionados, não é garantia de autoria. O que falta ser ensinado ao aluno em sala de aula é ser responsável pelo seu dizer, produzir um "novo" e não fazer cópias. Assim como Pacífico (2002) explicita "É possível inferir que, para produzir um texto com essa estrutura (introdução, desenvolvimento, conclusão), o sujeito tenha que conhecer o tema em questão, a fim de poder apresentá-lo e discuti-lo". É preciso que o professor instigue o aluno à leitura para que este constitua seu interdiscurso e consiga escrever seus textos.

Nas análises feitas, percebe-se que quatro dos cinco alunos permanecem no eixo do previsível, mesmo quando lhes é dada a oportunidade para escrever, sem exigência de estruturas de redação ou número máximo de linhas, os discentes escreveram a partir da ideologia dominante. Não se colocaram no texto, ou seja, não foram responsáveis pelo seu dizer, apenas colocaram argumentos retirados das coletâneas ou do que fora dito pelo professor e partiram da repetição formal. 
As análises evidenciam que trabalhar com a paráfrase e a polissemia não é algo fácil, mas também não é impossível. A dificuldade encontrada está no fato de que os alunos não escrevem desta forma porque simplesmente querem, mas, sim, porque desde quando foram alfabetizados são "lapidados" a escrever conforme pede a instituição de ensino, a qual prima pelo sentido dominante, cristalizado, ou seja, a paráfrase.

Em contrapartida, o Aluno-E mostrou-se autor de seu texto nas duas condições de produção. Isso só foi possível devido às histórias de leitura que o aluno possui, ou seja, ele já tinha um arquivo enriquecido, o qual fora suficiente para produzir os textos sobre o tema televisão.

Com este trabalho, pretende-se mostrar que o papel do professor é fundamental para a construção do aluno, pois aquele influencia este, principalmente quando se refere à leitura, o professor deve ser fonte de inspiração para seu aluno e deve instigá-lo a construir seu interdiscurso para que o aluno consiga escrever e defender seus argumentos sem precisar recorrer ao senso comum, mesmo porque este trabalho refere-se a alunos de terceiro ano do Ensino Médio que buscam uma vaga no vestibular. Há, ainda, a intenção de dar continuidade a esta pesquisa, de forma que desenvolva, sob a perspectiva da Análise do Discurso, algo que afete a assunção da autoria de alunos acostumados com a escrita parafrástica.

\section{REFERÊNCIAS}

CANGUILHEM, G. Le cerveau et la pensée. Cours Publics de MURS, 20 de fevereiro de 1990, p. 1 apud PÊCHEUX, M. Ler o arquivo hoje. In: ORLANDI, E. (org.). Gestos de Leituras: da história no discurso. Tradução Bethania Mariani et al. 2. ed. Campinas, São Paulo: Editora da Unicamp, 1997, p. 62.

COSTA, F. C. V. A tipologia discursiva e o discurso pedagógico: a autoria e a argumentação em textos escritos na/para a escola. In: NOLASCO, E.; GUERRA, V. (org.). Discurso, alteridades e gênero. São Carlos: Pedro \& João Editores, 2006, p. 253-270.

COSTA, F. C. V. Leitura e escrita: os gestos de interpretação na correção de textos escritos nos "laboratórios de redação" Estudos Linguísticos, São Paulo, v. 37, n. 3, p. 51-60, set dez. 2008. Disponível em: <http//www.gel.org.br/estudoslinguisticos/volumes/37/EL_V37N3 _06.pdf>. Acesso em 04. jul.2010.

FERNANDES, E. M. F. A escrita e a reescrita: os gestos da função-autor-leitor. In: INDURSKY, F.; FERREIRA, M. C. L.; MITTMANN, S. (org.). O Discurso na Contemporaneidade: Materialidades e Fronteiras. São Carlos: Claraluz, 2009, p. 405-416.

FOUCAULT, M. L'archéologie du savoir. Paris, Gallimard, 1969 apud ORLANDI, E. Discurso e Leitura. 3. ed. São Paulo: Cortez; Campinas, SP: Editora da Universidade Estadual de Campinas, 1996a. p. 53. 
GREGOLIN, M. R. V. Onde o autor é leitor todos os caminhos se bifurcam. In: GREGOLIN, M. R. et al (org). Análise do discurso: entornos do sentido. São Paulo: Cultura Acadêmica, 2001, p. 63-72 apud FERNANDES, E. M. F. A escrita e a reescrita: os gestos da funçãoautor-leitor. In: INDURSKY, F.; FERREIRA, M. C. L.; MITTMANN, S. (org.). O Discurso na contemporaneidade: materialidades e fronteiras. São Carlos: Claraluz, 2009, p. 409.

GUIMARÃES, E. Os Limites do sentido. Campinas: Pontes, 1995. 91p.

Texto e argumentação: um estudo das conjunções do português. 3. ed. Campinas: Pontes, 2002. 200p.

ORLANDI, E. Leitura: teoria e prática. Porto Alegre: Mercado Aberto. Ano 6, n. 9, 1987.

Discurso e leitura. 3. ed. São Paulo: Cortez; Campinas: Editora da Universidade Estadual de Campinas, 1996a. 120p.

Interpretação: autoria, leitura e efeitos do trabalho simbólico. 3. ed. Petrópolis, RJ: Vozes, 1996b. 154p.

Análise de discurso: princípios e procedimentos. 3. ed. Campinas: Pontes, 2001. $100 \mathrm{p}$. 2003. 276p.

.A linguagem e seu funcionamento: as formas do discurso. 4. ed. Campinas: Pontes,

PACÍFICO, S. M. R. Argumentação e autoria: o silenciamento do dizer. 2002. 190f. Tese (Doutorado). Faculdade de Filosofia, Ciências e Letras. Universidade de São Paulo. Ribeirão Preto.

. As posições de autor e leitor no jogo discursivo. In: TFOUNI, Leda Verdiani.

Múltiplas faces da autoria. Ijuí-RS: Unijuí, 2008, p. 237-254.

PÊCHEUX, M. Ler o arquivo hoje. In: ORLANDI, E. (org.). Gestos de leituras: da história no discurso. Tradução Bethania Mariani et al. 2. ed. Campinas, São Paulo: Editora da Unicamp, 1997a, p. 55-66.

. Semântica e discurso: uma crítica à afirmação do óbvio. Tradução de Eni P. Orlandi. 3. ed. Campinas: Editora da UNICAMP, 1997b. 320p.

RODRIGUES, S. L. Texto e autoria. In: RODRIGUES, S. L.; ORLANDI, E. (org.) Discurso e textualidade. Campinas: Pontes, 2006, p. 81-103

ROMÃO, L. M. S. E PACÍFICO, S. M. R. Era uma vez uma outra história: leitura e interpretação na sala de aula. São Paulo: DCL, 2006. 104p.

TFOUNI, L. V. Autoria e contenção da deriva. In: TFOUNI, L. V. (org.). Múltiplas faces da autoria. Ijuí, RS: Unijuí, 2008, p.141-158. 